\title{
A comparison between two different definitions of contrast-associated acute kidney injury for long-term mortality in patients with diabetes undergoing coronary angiography: a prospective cohort study
}

Zhubin Lun ${ }^{1,2,3+}$, Li Lei ${ }^{3,4+}$, Dianhua Zhou ${ }^{2 \dagger}$, Ming Ying ${ }^{3}$, Liwei Liü ${ }^{3,4}$, Guanzhong Chen ${ }^{3}$, Jin Liü ${ }^{3}$, Yibo He ${ }^{3}$, Huanqiang $\mathrm{Li}^{3}$, Zhidong Huang ${ }^{3}$, Yongquan Yang ${ }^{3}$, Jianfeng $\mathrm{Ye}^{2^{*}}$ and Yong Liu ${ }^{3^{*}}$ (])

\begin{abstract}
Background: The definitions of contrast-associated acute kidney injury (CA-AKI) are diverse and have different predictive effects for prognosis, which are adverse for clinical practice. Few articles have discussed the relationship between these definitions and long-term prognosis in patients with diabetes.

Methods: A total of 1154 diabetic patients who were undergoing coronary angiography (CAG) were included in this study. Two definitions of CA-AKI were used: $C A-A K I_{A}$ was defined as an increase $\geq 0.3 \mathrm{mg} / \mathrm{dl}$ or $>50 \%$ in serum creatinine ( $\mathrm{SCr}$ ) from baseline within $72 \mathrm{~h}$ after $C A G$, and $C A-A K I_{B}$ was defined as an increase $\geq 0.5 \mathrm{mg} / \mathrm{dl}$ or $>25 \%$ in $\mathrm{SCr}$ from baseline within $72 \mathrm{~h}$ after CAG. We used Cox regression to evaluate the association of these two CA-AKI definitions with long-term mortality and calculate the population attributable risks (PARs) of different definitions for long-term prognosis.

Results: During the median follow-up period of 7.4 (6.2-8.2) years, the overall long-term mortality was $18.84 \%$, and the long-term mortality in patients with CA-AKI according to both $C A-A K I_{A}$ and $C A-A K I_{B}$ Criteria were $36.73 \%$ and $28.86 \%$, respectively. We found that $C A-A K I_{A}(H R: 2.349,95 \% \mathrm{Cl} 1.570-3.517, p=0.001)$ and $C A-A K I_{B}(H R: 1.608,95 \%$ $\mathrm{Cl} 1.106-2.339, p=0.013)$ were associated with long-term mortality. The PARs were the highest for $C A-A K I_{A}(31.14 \%)$, followed by $C A-A K I_{B}(14.93 \%)$.
\end{abstract}

*Correspondence: yipjf@hotmail.com; liuyong@gdph.org.cn

${ }^{\dagger}$ Zhubin Lun, Li Lei and Dianhua Zhou have contributed equally to this

work

${ }^{2}$ Department of Cardiology, Dongguan TCM Hospital, Dongguan 523000,

China

${ }^{3}$ Department of Cardiology, Guangdong Provincial Key Laboratory of Coronary Heart Disease Prevention, Guangdong Cardiovascular Institute, Guangdong Provincial People's Hospital, The Affiliated Guangdong Provincial People's Hospital of South China University of Technology, Guangdong Academy of Medical Sciences,

Guangzhou 510080, China

Full list of author information is available at the end of the article

(c) The Author(s) 2020. Open Access This article is licensed under a Creative Commons Attribution 4.0 International License, which permits use, sharing, adaptation, distribution and reproduction in any medium or format, as long as you give appropriate credit to the original author(s) and the source, provide a link to the Creative Commons licence, and indicate if changes were made. The images or other third party material in this article are included in the article's Creative Commons licence, unless indicated otherwise in a credit line to the material. If material is not included in the article's Creative Commons licence and your intended use is not permitted by statutory regulation or exceeds the permitted use, you will need to obtain permission directly from the copyright holder. To view a copy of this licence, visit http://creativecommons.org/licenses/by/4.0/. The Creative Commons Public Domain Dedication waiver (http://creativeco mmons.org/publicdomain/zero/1.0/) applies to the data made available in this article, unless otherwise stated in a credit line to the data. 
Conclusions: CA-AKI is a common complication in diabetic patients receiving CAG. The two CA-AKI definitions are significantly associated with a poor long-term prognosis, and CA-AKI , with the highest PAR, needs more clinical attention.

Keywords: Contrast-associated acute kidney injury, Diabetes, Definitions, Long-term mortality, Population attributable risks

\section{Introduction}

Contrast-associated acute kidney injury (CA-AKI) is a common complication after coronary angiography that is closely related to adverse clinical prognoses such as cardiovascular disease, renal events, and long-term mortality [1-3]. CA-AKI is usually defined as an increase in serum creatinine $(\mathrm{SCr}) \geq 50 \%$ or $\geq 0.3 \mathrm{mg} / \mathrm{dl}$ within $72 \mathrm{~h}$ after exposure to a contrast agent, but the definition of CA-AKI is not limited to this. It is defined as an increase in $\mathrm{SCr}$ by $0.5 \mathrm{mg} / \mathrm{dl}$ or $25 \%$ within $72 \mathrm{~h}$ after using a contrast agent, which has also been confirmed in many clinical studies. In fact, the incidence and prognostic value of CA-AKI are different with different definitions [4-8]. It has been found that different definitions have different efficacies in predicting long-term mortality in STEMI patients, and the criteria of the Acute Kidney Injury Network (AKIN) has better efficacy [4]. Different definitions also have different performances in terms of populationattributable risk (PAR) in AMI patients; the standard definition, which is an increase in $\mathrm{SCr} \geq 50 \%$ or $\geq 0.3 \mathrm{mg} /$ dl within 72, has the highest PAR [6]. In previous studies, diabetes mellitus was considered a risk factor for CA-AKI, and it has been applied to several high-efficacy predictive models for CA-AKI [9-11]. However, to date, there are few articles comparing the association between different definitions and long-term prognosis in diabetic patients.

Therefore, we evaluated the association between different definitions of CA-AKI and long-term mortality in diabetic patients after coronary angiography in this article.

\section{Methods}

\section{Study design and population}

This is a single-center prospective observational study (PROCOMIN, ClinicalTrials.gov NCT01400295). From January 2010 to December 2013, 1154 consecutive patients aged $\geq 18$ years who were diagnosed with diabetes underwent coronary angiography in Guangdong Provincial People's Hospital and were included in the study. Exclusion criteria included pregnancy, lactation, intravascular administration of contrast media within 7 days before the operation or 3 days after the operation, no use of low osmotic pressure contrast media, cardiovascular surgery or intravascular repair, end-stage renal disease or kidney replacement, creatinine deficiency before or after the operation, malignant tumor and no use of isotonic saline for hydration [12]. The research was approved by the ethics research committee of our institute, and patient informed consent was obtained (approval number: GDREC2010112H).

\section{Study protocol}

According to the current guidelines, patients underwent coronary angiography, including standard clinical practice with standard guide catheters/guidewires/balloon catheters/stents via the femoral or radial approach. Contrast media, drugs and intra-aortic balloon pump (IABP) support were all used by cardiovascular physicians according to the patients' conditions and guidelines. In addition, all patients were administered nonionic hypotonic early contrast media. From $2-12 \mathrm{~h}$ before surgery to $6-24 \mathrm{~h}$ after surgery, isotonic saline was given at a rate of $1 \mathrm{ml} / \mathrm{kg} / \mathrm{h}$, and the hydration rate of patients with heart failure and a left ventricular ejection fraction $\leq 40 \%$ was halved. SCr concentrations were measured on days 1 , 2 , and 3 in all patients before and after surgery.

\section{Clinical definitions and follow-up}

Long-term mortality was defined as all-cause death at the latest follow-up. Diabetes was defined as a previous diagnosis of diabetes or an $\mathrm{HbAlc}$ level $\geq 6.5(48 \mathrm{mmol} / \mathrm{mol})$. $\mathrm{CA}-\mathrm{AKI}_{\mathrm{A}}$ was defined as an increase in serum creatine by $0.3 \mathrm{mg} / \mathrm{dl}$ or $50 \%$ within $72 \mathrm{~h}$ after the procedure, while $\mathrm{CA}-\mathrm{AKI}_{\mathrm{B}}$ was defined as an increase in SCr by $0.5 \mathrm{mg} /$ $\mathrm{dl}$ or $25 \%$ within $72 \mathrm{~h}$ after the procedure [13-16]. Anemia was defined as a baseline hematocrit value $<39 \%$ for men or $<36 \%$ for women according to the World Health Organization criteria [17]. Congestive heart failure (CHF) was defined as New York Heart Association (NYHA) functional class $>2$, Killip class $>1$ or pulmonary edema. SBP $<80 \mathrm{mmHg}$ for at least $1 \mathrm{~h}$ during the perioperative use of positive inotropic force or hemodynamic balance with IABP was considered hypotension. The formula for eGFR used was the modified diet in renal disease formula $(186 \times \mathrm{SCr}(\mathrm{mg} / \mathrm{dL})-1.154 \times$ age $-0.203 \times$ (0.742 for women). At 3, 6, 12, 18, and 24 months after coronary angiography, office follow-up visits and telephone interviews were conducted by professionals, and subsequent clinical events were monitored and recorded. 


\section{Statistical analysis}

Continuous variables are presented as the mean \pm SD or median $\pm I Q R$, and we used Wilcoxon rank-sum tests or Student's t-test to compare the differences between two independent samples (with CA-AKI and without CA-AKI) using different definitions. For categorical variables expressed as counts (percentages), we used the Chi-square test or Fisher's exact test to verify the difference. For the first step, we used a univariate logistic model to analyze the data to identify the predictors of $C A-A K I_{A}$ and $C A-A K I_{B}$. The results of this analysis are shown as odds ratios and $95 \%$ confidence intervals (CIs). Multivariate logistic analysis was also used. Kaplan-Meier analysis was used to calculate cumulative mortality using different definitions, and the differences between the curves were evaluated with the log-rank test. We used a multivariate Cox regression model adjusting for other risk factors (e.g., age, AMI, hypotension, HS-CRP) to show the relationship between CA-AKI and long-term mortality. The adjusted risk factors in the univariate Cox regression analysis were selected based on previous studies and clinical importance $[18,19]$. Two multivariate Cox proportional hazard regression models were applied for the two different definitions of CA-AKI. The PAR was calculated by the following equation: $\mathrm{PAR}=\mathrm{P}(\mathrm{HR}-1)$ / $[1+\mathrm{P}(\mathrm{HR}-1)]$, where $\mathrm{p}$ is the incidence of CA-AKI using different definitions in the database. The standard error of the PAR was calculated using the delta method. A two-sided probability value $<0.05$ was considered significant. All data analyses were conducted with SAS version 9.4 (SAS Institute, Cary, NC) and R software (version 4.0.0; R Core Team, Vienna, Austria).

\section{Results}

\section{Patient characteristics}

A total of 1154 consecutive diabetic patients who received coronary angiography were included in the analysis. The demographic, clinical and procedural characteristics of patients with or without CAAKI are shown in Table 1. Overall, the mean age was $64.46 \pm 10.55$ years, with females accounting for just under one-third of the population (27.73\%). Only 213 patients (18.5) were age $\geq 75$ years. The number of persons diagnosed with CAD, CHF and eGFR $<60 \mathrm{ml} /$ $\mathrm{min} / 1.73 \mathrm{~m}^{2}$ was 1074,733 and 268 , respectively. The usage rates of ACEIs/ARBs, beta-blockers, statins and diuretics were $89.08 \%, 84.84 \%, 97.57 \%$ and $22.62 \%$, respectively. A total of $710(61.53 \%)$ patients underwent PCI. The mean dose of contrast agent was $131.55 \pm 63.85$, and the median follow-up period of 7.4 $(6.2-8.2)$ years.
Incidence of CA-AKI by the CA-AKI $I_{A}$ and $C A-A K I_{B}$ criteria According to the $\mathrm{CA}-\mathrm{AKI}_{\mathrm{A}}$ criteria, CA-AKI occurred in 98 patients $(8.49 \%)$, while according to the $\mathrm{CA}-\mathrm{AKI}_{\mathrm{B}}$, CA-AKI occurred in 149 patients (12.91\%). Among 98 patients with $\mathrm{CA}-\mathrm{AKI}_{\mathrm{A}}, 86$ patients met the criteria for $\mathrm{CA}-\mathrm{AKI}_{\mathrm{B}}$. On the other hand, among 149 patients with $\mathrm{CA}-\mathrm{AKI}_{\mathrm{B}}, 86$ patients met the criteria for $\mathrm{CA}-\mathrm{AKI}_{\mathrm{A}}$. However, regardless of the definition of CA-AKI, patients with CA-AKI were older, had a reduced LVEF, and had more basic diseases. The usage of ACEIs/ARBs and betablockers in patients with $\mathrm{CA}-\mathrm{AKI}_{\mathrm{A}}$ was lower, but there was no significant difference from those with $C A-A K I_{B}$. Similarly, we found no significant association between CA-AKI and non-CA-AKI patients in terms of statin drug use (Table 1).

\section{Incidence and predictors of long-term mortality}

During the median follow-up period of $7.4(6.2-8.2)$ years, the overall long-term mortality was $18.84 \%$, and the long-term mortality in patients with CA-AKI according to the $\mathrm{CA}-\mathrm{AKI}_{\mathrm{A}}$ and $\mathrm{CA}-\mathrm{AKI}_{\mathrm{B}}$ criteria was $36.73 \%$ and $28.86 \%$, respectively. Kaplan-Meier curves showed that the long-term prognosis of patients with CA-AKI was worse than that of those without CA-AKI according to the two definitions of CA-AKI $(\log$-rank $p<0.01$; Fig. 1).

The univariate and multivariate analyses of risk factors for long-term mortality are shown in Table 2 and Fig. 2. The analysis showed that the independent predictive factors related to long-term mortality are age $\geq 75$ years, AMI, hypotension, HS-CRP and CA-AKI. As expected, there was an increased risk of long-term mortality associated with CA-AKI. CA-AKI ${ }_{\mathrm{A}}$ and $\mathrm{CA}-\mathrm{AKI}_{\mathrm{B}}$ increased the long-term mortality risk by 2.349 and 1.608 times, respectively (95\% CI $1.570-3.516$ and $95 \%$ CI $1.106-$ 2.339 , respectively).

\section{PARs of CA-AKI by CA-AKI $A$ and CA-AKI ${ }_{B}$ criteria}

Between the two definitions of CA-AKI, the prevalence of $\mathrm{CA}-\mathrm{AKI}_{\mathrm{A}}$ was $8.49 \%$, while the prevalence of CA$\mathrm{AKI}_{\mathrm{B}}$ was $12.91 \%$. The PAR of CA-AKI $\mathrm{A}$ was significantly higher than that of CA-AKI ${ }_{B}[31.14 \%$ (95\% CI 17.3148.03\%) vs $14.93 \%$ (95\% CI 2.97-27.87\%)] (Fig. 3).

\section{Discussion}

We analyzed the relationship between different definitions of CA-AKI and long-term prognosis in diabetic patients and compared the PARs of long-term mortality. According to our findings, the incidence of $C A-\mathrm{AKI}_{\mathrm{A}}$ was slightly lower than that of $\mathrm{CA}-\mathrm{AKI}_{\mathrm{B}}$, while the mortality rate was the opposite. In addition, we also found that the mortality rate of patients with CA-AKI was higher 
Table 1 Baseline characteristics

\begin{tabular}{|c|c|c|c|c|c|c|c|}
\hline \multirow[t]{2}{*}{ Variables } & \multirow{2}{*}{$\begin{array}{l}\text { Total } \\
(n=1154)\end{array}$} & \multicolumn{3}{|l|}{$\mathrm{CA}-\mathrm{AKI}_{\mathrm{A}}$} & \multicolumn{3}{|l|}{ CA-AKI } \\
\hline & & $\begin{array}{l}\text { Yes } \\
(n=98)\end{array}$ & $\begin{array}{l}\text { No } \\
(n=1056)\end{array}$ & $p$ value & $\begin{array}{l}\text { Yes } \\
(n=149)\end{array}$ & $\begin{array}{l}\text { No } \\
(n=1005)\end{array}$ & $p$ value \\
\hline Age, y & $64.46 \pm 10.55$ & $70.24 \pm 9.45$ & $63.92 \pm 10.49$ & $<0.001$ & $66.42 \pm 11.41$ & $64.17 \pm 10.39$ & 0.024 \\
\hline Age $\geq 75, n(\%)$ & $213(18.5)$ & $37(37.8)$ & $176(16.7)$ & $<0.001$ & $41(27.5)$ & $172(17.1)$ & 0.003 \\
\hline Female sex, n (\%) & $320(27.73)$ & $34(34.69)$ & $286(27.08)$ & 0.107 & 49 (32.89) & $271(26.97)$ & 0.132 \\
\hline Weight, kg & $66.48 \pm 10.68$ & $64.3 \pm 11.42$ & $66.68 \pm 10.59$ & 0.050 & $65.60 \pm 11.45$ & $66.61 \pm 10.56$ & 0.312 \\
\hline $\mathrm{SBP}, \mathrm{mmHg}$ & $131.12 \pm 20.80$ & $131.42 \pm 27.21$ & $131.09 \pm 20.12$ & 0.906 & $129.00 \pm 24.58$ & $131.43 \pm 20.17$ & 0.251 \\
\hline $\mathrm{DBP}, \mathrm{mmHg}$ & $76.65 \pm 12.06$ & $77.10 \pm 13.99$ & $76.61 \pm 11.87$ & 0.738 & $76.64 \pm 13.41$ & $76.65 \pm 11.85$ & 0.988 \\
\hline $\mathrm{HR}, \mathrm{bpm}$ & $76.39 \pm 13.99$ & $81.13 \pm 17.17$ & $75.95 \pm 13.59$ & 0.005 & $79.01 \pm 16.14$ & $76.00 \pm 13.61$ & 0.032 \\
\hline CHF, n (\%) & $733(63.52)$ & $79(80.61)$ & $654(61.93)$ & $<0.001$ & $106(71.14)$ & $627(62.39)$ & 0.042 \\
\hline CAD, n (\%) & $1074(93.07)$ & $96(97.96)$ & $978(92.61)$ & 0.054 & 139 (93.29) & 935 (93.03) & 0.991 \\
\hline Hypotension, n (\%) & $22(1.91)$ & $9(9.18)$ & $13(1.23)$ & $<0.001$ & $11(7.38)$ & $11(1.09)$ & $<0.001$ \\
\hline LVEF, \% & $56.97 \pm 13.05$ & $50.54 \pm 13.57$ & $57.59 \pm 12.84$ & $<0.001$ & $53.15 \pm 13.72$ & $57.56 \pm 12.85$ & $<0.001$ \\
\hline LVEF < 40\%, n (\%) & $119(10.31)$ & $18(18.37)$ & $101(9.56)$ & 0.011 & $23(15.44)$ & $96(9.55)$ & 0.046 \\
\hline Hypertension, n (\%) & $777(67.33)$ & $75(76.53)$ & $702(66.48)$ & 0.044 & $103(69.13)$ & $674(67.06)$ & 0.628 \\
\hline Anemia, n (\%) & $407(35.27)$ & $49(50.00)$ & $358(33.90)$ & 0.001 & $56(37.58)$ & $351(34.93)$ & 0.561 \\
\hline AMI, n (\%) & $379(32.84)$ & $56(57.14)$ & $323(30.59)$ & $<0.001$ & $76(51.01)$ & $303(30.15)$ & $<0.001$ \\
\hline $\mathrm{eGFR}<60 \mathrm{ml} / \mathrm{min} / 1.73 \mathrm{~m}^{2}, \mathrm{n}(\%)$ & $268(23.2)$ & $33(33.7)$ & $235(22.3)$ & 0.016 & $41(27.5)$ & $227(22.6)$ & 0.230 \\
\hline LDL-C, mmol/L & $2.67 \pm 0.96$ & $2.99 \pm 1.05$ & $2.65 \pm 0.95$ & 0.009 & $2.97 \pm 1.28$ & $2.63 \pm 0.90$ & 0.007 \\
\hline $\mathrm{HDL}-\mathrm{C}, \mathrm{mmol} / \mathrm{L}$ & $1.01 \pm 2.20$ & $0.94 \pm 0.24$ & $1.02 \pm 2.28$ & 0.340 & $0.95 \pm 0.26$ & $1.02 \pm 2.35$ & 0.365 \\
\hline $\mathrm{HS}-\mathrm{CRP}, \mathrm{mg} / \mathrm{L}$ & $19.02 \pm 37.45$ & $38.72 \pm 51.47$ & $17.04 \pm 35.18$ & $<0.001$ & $31.99 \pm 46.06$ & $16.91 \pm 35.45$ & $<0.001$ \\
\hline $\mathrm{SCR}, \mu \mathrm{mol} / \mathrm{L}$ & $96.09 \pm 47.36$ & $126.4 \pm 62.6$ & $93.28 \pm 44.69$ & $<0.001$ & $96.07 \pm 54.58$ & $96.10 \pm 46.22$ & 0.996 \\
\hline Hemoglobin, g/L & $131.03 \pm 16.30$ & $122.34 \pm 20.22$ & $131.74 \pm 15.73$ & $<0.001$ & $130.11 \pm 18.34$ & $131.15 \pm 16.01$ & 0.552 \\
\hline $\mathrm{HbA} 1 \mathrm{c}, \%$ & $7.60 \pm 1.53$ & $7.79 \pm 1.60$ & $7.58 \pm 1.52$ & 0.250 & $130.11 \pm 18.34$ & $131.15 \pm 16.01$ & 0.830 \\
\hline Serum albumin, g/L & $35.09 \pm 4.59$ & $31.81 \pm 5.27$ & $35.35 \pm 4.43$ & $<0.001$ & $33.90 \pm 5.58$ & $35.25 \pm 4.43$ & 0.013 \\
\hline ACEI/ARB, n (\%) & $1028(89.08)$ & $81(82.65)$ & $947(89.68)$ & 0.033 & $131(87.92)$ & $897(89.25)$ & 0.626 \\
\hline Beta-blocker, n (\%) & $979(84.84)$ & $71(72.45)$ & $908(85.98)$ & $<0.001$ & $120(80.54)$ & $859(85.47)$ & 0.110 \\
\hline Statin, n (\%) & $1126(97.57)$ & $94(95.92)$ & $1032(97.73)$ & 0.290 & $145(97.32)$ & $981(97.61)$ & 0.776 \\
\hline Diuretics, n (\%) & $261(22.62)$ & $49(50.00)$ & $212(20.08)$ & $<0.001$ & $57(38.26)$ & $204(20.30)$ & $<0.001$ \\
\hline Metformin, n (\%) & $79(6.85)$ & $2(2.04)$ & $77(7.29)$ & 0.085 & $7(4.70)$ & $72(7.16)$ & 0.422 \\
\hline $\mathrm{PCl}, \mathrm{n}(\%)$ & $710(61.53)$ & $58(59.18)$ & $652(61.74)$ & 0.160 & $89(59.73)$ & $621(61.79)$ & 0.174 \\
\hline $\mathrm{CV}, \mathrm{mL}$ & $131.55 \pm 63.85$ & $137.09 \pm 63.05$ & $131.04 \pm 63.93$ & 0.366 & $130.27 \pm 63.2$ & $131.74 \pm 63.98$ & 0.791 \\
\hline Periprocedure IABP, n (\%) & $59(5.11)$ & $25(25.51)$ & $34(3.22)$ & $<0.001$ & $23(15.44)$ & $36(3.58)$ & $<0.001$ \\
\hline Mehran score & $6.37 \pm 4.53$ & $11.08 \pm 6.35$ & $5.92 \pm 4.04$ & $<0.001$ & $8.36 \pm 6.09$ & $6.07 \pm 4.17$ & $<0.001$ \\
\hline
\end{tabular}

$C A-A K I$ contrast-associated acute kidney injury, $S B P$ systolic blood pressure, $D B P$ diastolic blood pressure, $H R$ heart rate, $C H F$ chronic heart failure, $C A D$ coronary artery disease, $L V E F$ left ventricular ejection fraction, $L D L-C$ low-density lipoprotein-C, $H D L-C$ high-density lipoprotein- $C, H S-C R P$ high-sensitivity $C$-reactive protein, $S C R$ serum creatinine, $L p a$ lipoprotein a, eGFR estimated glomerular filtration rate, $A C E I$ angiotensin-converting enzyme inhibitor, $A R B$ angiotensin receptor blocker, $P C I$ percutaneous coronary intervention, $C V$ contrast volume, IABP intra-aortic balloon pump

than that of patients without CA-AKI. After adjusting for demography, drugs and cardiorenal risk factors, an increased risk of long-term mortality was associated with $\mathrm{CA}-\mathrm{AKI}_{\mathrm{A}}$ and $\mathrm{CA}-\mathrm{AKI}_{\mathrm{B}}$. However, $\mathrm{CA}-\mathrm{AKI}_{\mathrm{A}}$ was associated with higher risk of long-term mortality and PAR than CA-AKI $\mathrm{B}_{\mathrm{B}}$.

Without a uniform definition, the incidence of CA-AKI was between 8.49 and $12.91 \%$ in patients with diabetes mellitus undergoing coronary angiography. The incidence of CA-AKI in patients with diabetes indicated in
Chalikias's review was similar [20]. Our results suggest that regardless of how CA-AKI is defined, it leads to a poor long-term prognosis. In a study discussing the clinical significance of CA-AKI, CA-AKI was associated with death compared with non-CA-AKI, even when different definitions of CA-AKI were applied [5]. This further confirmed those results. On the other hand, in a study with a median follow-up period of $365 \pm 130$ days, Centola et al. compared the effects of different definitions of CAAKI on long-term death in 402 patients with STEMI and 


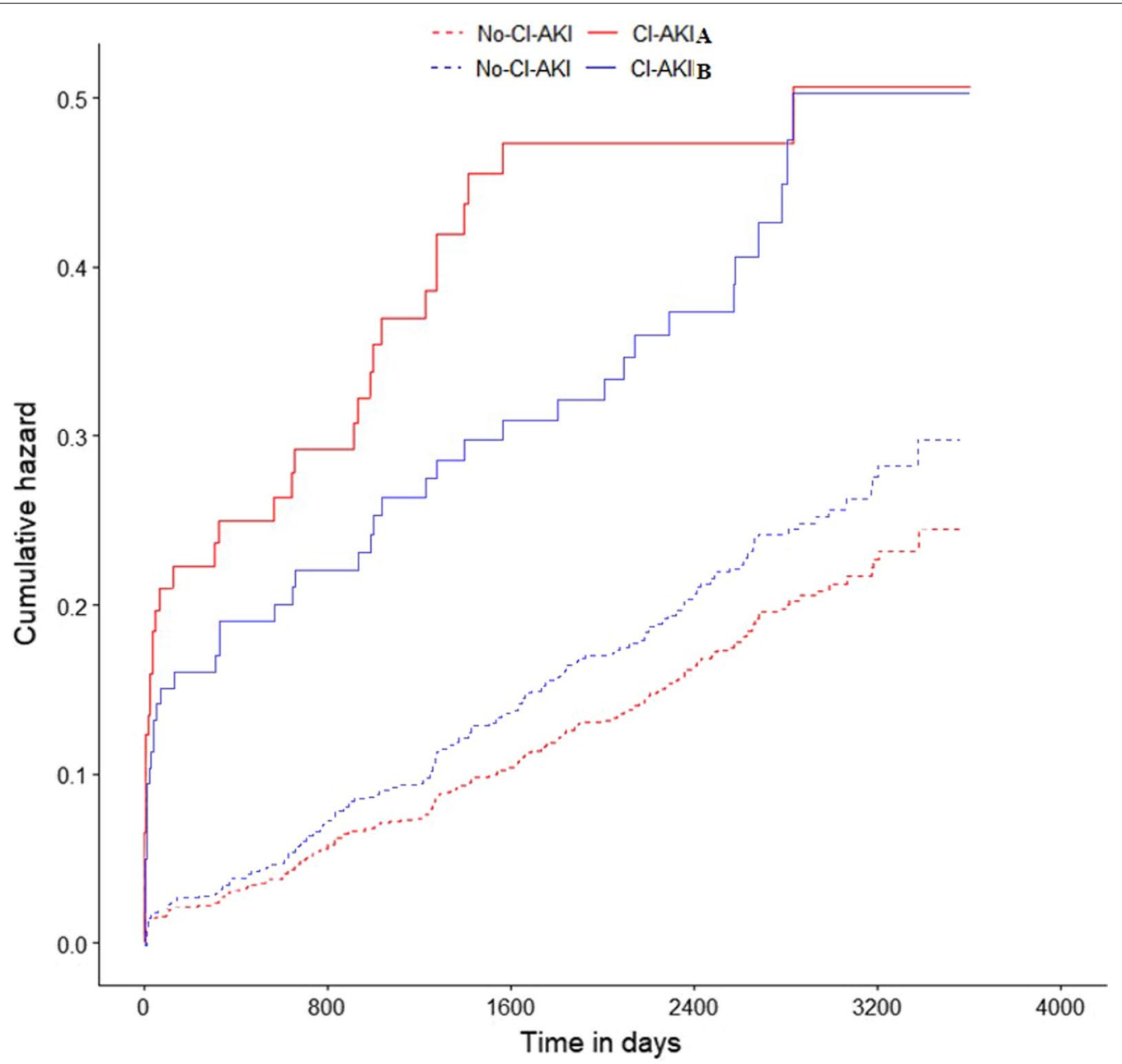

Fig. 1 Association between contrast-associated acute kidney injury and long-term mortality in diabetic patients with undergoing coronary angiography

found that each different definition increased the risk of death [4]. CA-AKI may be an important risk factor for long-term mortality, rather than an intermediate, which is similar to Mehran's recently described viewpoint [21]. The research of Lassnigg et al. also supports this view, and they found that a small increase or decrease in serum creatinine was significantly related to death [22]. Fluctuation in serum creatinine may be due to unstable hemodynamics, and the downstream adverse events have little relevance.

As far as we know, few studies have compared the relationship between different definitions of CA-AKI and long-term mortality in diabetic patients. However, we evaluated the correlation between the two definitions of CA-AKI and long-term mortality in diabetic patients by cox regression analysis and PAR calculation. The significance of population attributable risk (PAR) is the proportion of cases that would not happen in the population without risk factors. Chen et al. also found that the $1^{\text {st }}$ most common definition of CA-AKI $(\geq 0.3 \mathrm{mg} / \mathrm{dl}$ or $\geq 50 \%)$ and the $2^{\text {nd }}$ most common definition of CAAKI $(\geq 0.5 \mathrm{mg} / \mathrm{dl}$ or $\geq 25 \%$ ) have different predictive powers for long-term mortality risk, and the 1st most common definition of CA-AKI is more closely related to all-cause death [5]. Recently, Lei et al. found that three different definitions of CA-AKI were also inconsistent in predicting death in AMI patients. Their conclusion was that the highest PAR was found in CA-AKI ${ }_{A}$ (a SCr elevation $\geq 50 \%$ or $\geq 0.3 \mathrm{mg} / \mathrm{dl}$ within $72 \mathrm{~h}$ ), which is consistent with our results [6]. Benoit Guillon and his colleagues showed that the CA-AKI defined by $\mathrm{SCr}$ absolute increase $\geq 0.3 \mathrm{mg} / \mathrm{dl}$ or $\geq 50 \%$ over baseline was strongly correlated with 6 months all-cause death in patients with CAG [7]. And Gabriele Pesarini et al. found that an absolute increase of $\mathrm{SCr}>0.3 \mathrm{mg} / \mathrm{dl}$ seems to be the most clinically meaningful cut-off value for CA-AKI and 
Table 2 Univariable analysis of risk factors for long-term mortality

\begin{tabular}{|c|c|c|c|}
\hline & \multicolumn{3}{|c|}{ Univariable analysis } \\
\hline & HR & $95 \% \mathrm{Cl}$ & $p$ value \\
\hline Age $\geq 75$ & 1.016 & $1.002-1.029$ & 0.021 \\
\hline Female sex & 0.976 & $0.723-1.318$ & 0.875 \\
\hline Weight & 0.995 & $0.983-1.008$ & 0.472 \\
\hline Smoking & 1.065 & $0.846-1.341$ & 0.593 \\
\hline $\mathrm{CHF}$ & 1.545 & $1.134-2.106$ & 0.006 \\
\hline AMI & 1.837 & $1.404-2.402$ & $<0.001$ \\
\hline Anemia & 1.192 & $0.906-1.569$ & 0.211 \\
\hline $\mathrm{eGFR}<60 \mathrm{ml} / \mathrm{min} / 1.73 \mathrm{~m}^{2}$ & 1.127 & $0.828-1.534$ & 0.448 \\
\hline Hypertension & 0.912 & $0.690-1.205$ & 0.517 \\
\hline Hypotension & 4.047 & $2.149-7.661$ & $<0.001$ \\
\hline HS-CRP, mg/L & 1.006 & $1.003-1.009$ & $<0.001$ \\
\hline ACEI/ARB & 0.702 & $0.480-1.026$ & 0.068 \\
\hline Beta-blocker & 0.649 & $0.468-0.902$ & 0.010 \\
\hline Diuretic & 1.486 & $1.175-1.881$ & 0.001 \\
\hline IABP & 3.883 & $1.443-10.450$ & 0.007 \\
\hline CV & 1.001 & $0.999-1.003$ & 0.415 \\
\hline$C A-A K I_{A}$ & 2.821 & $1.973-4.038$ & $<0.001$ \\
\hline$C A-A K I_{B}$ & 1.926 & $1.380-2.690$ & $<0.001$ \\
\hline
\end{tabular}

$C A-A K I$ contrast-associated acute kidney injury, $C H F$ chronic heart failure, $A M I$ acute myocardial infarction, $H S$-CRP high-sensitivity C-reactive protein, $A C E I$ angiotensin-converting enzyme inhibitor, $A R B$ angiotensin receptor blocker, $P C l$ percutaneous coronary intervention, $C V$ contrast volume, IABP intra-aortic balloon pump

continuous renal damage monitoring [23]. These studies have shown that different definitions of CA-AKI have different strengths of association with death, and CA-AKI defined as $\mathrm{SCr}$ elevation $\geq 50 \%$ or $\geq 0.3 \mathrm{mg} / \mathrm{dl}$ within $72 \mathrm{~h}$ has a stronger association with long-term mortality. This further confirmed our results. Our results show that the HR and PAR of CA-AKI $I_{A}$ were higher than those of $\mathrm{CA}-\mathrm{AKI}_{\mathrm{B}}$, which indicates that the $\mathrm{CA}-\mathrm{AKI}_{\mathrm{A}}$ definition is more closely related to long-term mortality. On the one hand, this may be related to the patient we included, and diabetic patients belong to high-risk groups. In a long-term hyperglycemic environment, HbAlc increases, oxygenated hemoglobin decreases, and microvascular perfusion is insufficient, which leads to kidney ischemia and hypoxia and aggravated kidney injury. On the other hand, when the "restrictive" criteria are adopted (an increase $\geq 0.5 \mathrm{mg} / \mathrm{dl}$ in $\mathrm{SCr}$ above baseline), patients with slight increase in serum creatinine may be ignored, which will have an impact on long-term death. When the "relativity" criteria (an increase in $\mathrm{SCr}>25 \%$ above baseline) are adopted, the recognition ability will be reduced [24]. For example, in Gajewska's research, it was found that the renal damage caused by $\mathrm{SCr}$ increased from 1.2 to $1.6 \mathrm{mg} / \mathrm{dl}$ was much higher than that caused by $\mathrm{SCr}$ increased from 3.0 to $3.75 \mathrm{mg} / \mathrm{dl}$ [25]. In addition, in previous studies, mild increases in serum creatinine in patients with lower baseline serum creatinine are more likely to lead to significant deterioration of renal function. The majority of diabetic patients often have renal insufficiency, and a slight increase in "restrictive" criteria $(\geq 0.3 \mathrm{mg} / \mathrm{dl}$ or $\geq 0.5 \mathrm{mg} / \mathrm{dl})$ often cannot truly reflect the occurrence of kidney injury in diabetic patients. The "relativity" criteria are often more able to reflect the exact kidney damage based on the poor baseline renal function.

After adjusting for AMI, hypotension and HS-CRP, we found that CA-AKI was significantly associated with long-term mortality. AMI, hypotension and HS-CRP are the research hotspots of CA-AKI and prognosis. The association between AMI and CA-AKI has been confirmed in previous studies [26, 27], and Zafrir et al. also found that patients with AMI can have significantly increased long-term mortality [28]. Hypotension, as a strong predictor of CA-AKI, is also a good predictor of death. Compared with the risk found in our long-term follow-up, Chong et al. found that patients with hypotension had a high risk of death at 6 months [29]. As for HS-CRP, it is an important indicator of inflammation. In Xiao-Sheng Guo's et al. study, the inflammatory response was found to be an important mechanism for the occurrence of CA-AKI, and the risk of long-term mortality was also increased with an HS-CRP level $>7.3 \mathrm{mg} / \mathrm{l}$ [30]. The reliability of our analysis can be further enhanced by adjusting for variables of clinical significance.

At present, there were various definitions of CA-AKI [20], which makes clinicians confused about the diagnosis of CA-AKI. We confirmed that CA-AKI is an independent risk factor for long-term mortality in patients with diabetes, and the definition of $\mathrm{CA}-\mathrm{AKI}_{\mathrm{A}}$ is more suitable for diabetic patients than $\mathrm{CA}-\mathrm{AKI} \mathrm{B}_{\mathrm{B}}$ for assessing the relationship between CA-AKI and prognosis. At the same time, the strict definition of CA-AKI can prompt a poor prognosis. This is helpful for clinicians to identify and manage high-risk CA-AKI patients that are highly related to long-term death, which improving the prognosis. We found that among patients with diabetes, the definition of $\mathrm{CA}-\mathrm{AKI}_{\mathrm{A}}$ is more suitable for assessing the relationship between disease and prognosis, and more attention and care should be given to $\mathrm{CA}-\mathrm{AKI}_{\mathrm{A}}$ patients in clinical practice. The comparison of the definition is helpful for medical staff to identify the patients with CA-AKI who are most related to long-term adverse prognosis in highrisk groups (such as heart failure, chronic kidney disease, anemia, or diabetes), so as to carry out accurate management. This method of using cox regression analysis and PAR for comparison of definitions in high-risk patients to guide clinical management is worthy of promotion. Our study did not evaluate the impact of the progression 


\section{$\mathrm{HR}(95 \% \mathrm{CI})$ for long-term mortality}

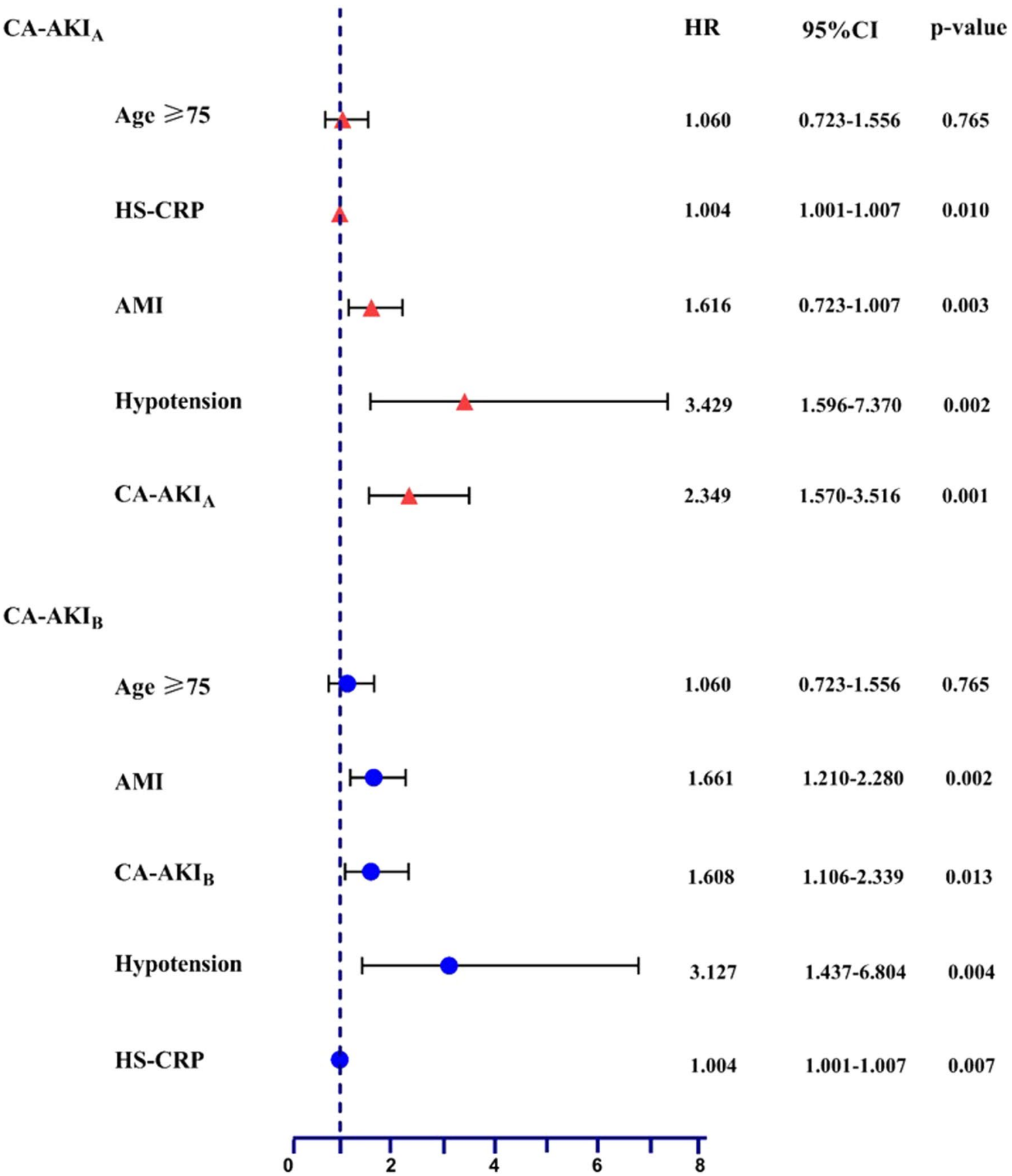

Fig. 2 Multivariable analysis of risk factors for long-term mortality

of renal function on long-term mortality due to the lack of $\mathrm{SCr}$ during follow-up. In the study of Nemoto et al., patients with CA-AKI were more likely to suffer persistent impairment of renal function, which strongly affects long-term prognosis [31]. This may affect our results and has become a major limitation of our research.
Our research has several limitations. First, the patients we included in the study were diabetic patients, which will reduce the generalizability of the findings. Second, our study was only a sub-study of a single-center prospective observational study in South China, and the prevalence of CA-AKI was not significant. However, we are the 


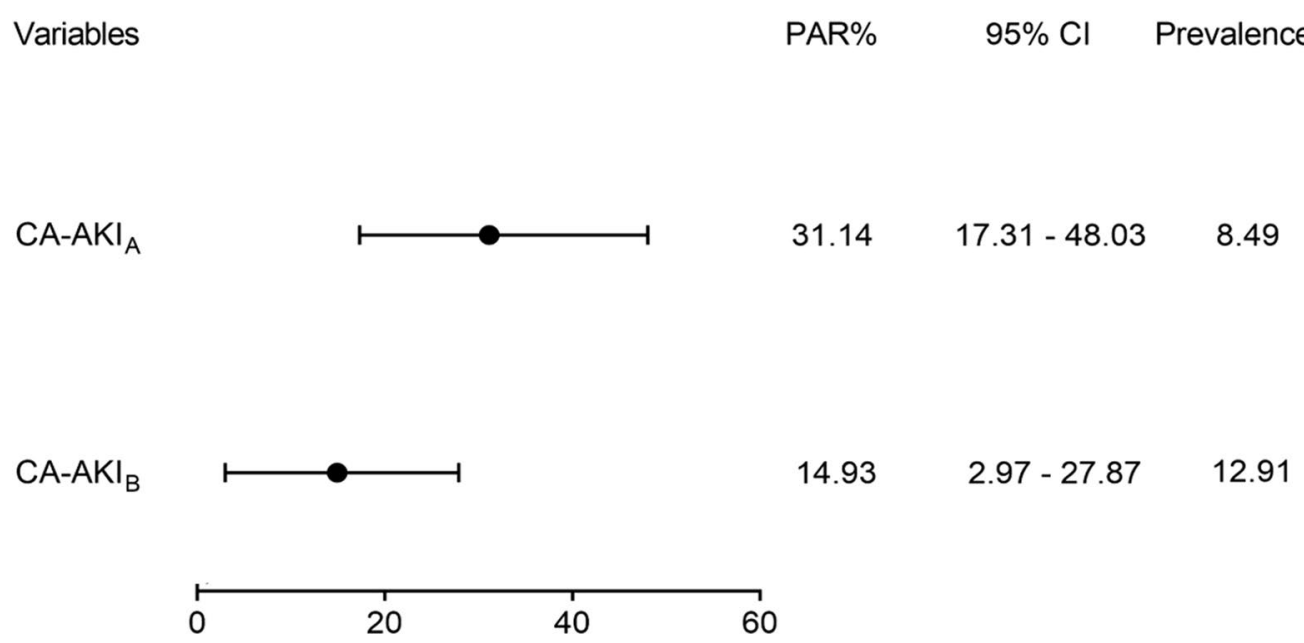

Fig. 3 Population attributable risk of two different definitions of contrast-associated acute kidney injury

first to explore the relationship between the definition of CA-AKI and long-term prognosis in diabetic patients, and we also found that our results were similar to those reported in previous studies involving high-risk groups. Third, we conclude that preventing the occurrence of CA-AKI can reduce the risk of long-term mortality but cannot directly confirm this conclusion. However, our study evaluated the association between CA-AKI and long-term death by calculating PAR and further verified the results of the multivariate analysis. Fourth, due to the limitation of the sample size of our study, the variables for multivariable analysis adjustment were limited. However, long-term mortality (all-cause mortality) was multifactorial and complicated. In addition, most of the patients included in our study had coronary artery disease. During follow-up, they may be more prone to cardiovascular mortality. This long-term mortality (all-cause mortality) is more close to cardiovascular mortality. Fifth, we lacked the SCr data of patients during the follow-up and were unable to assess the progression of renal insufficiency, which may have an impact on our results. However, we also adjusted for clinically significant variables related to long-term mortality in the multivariate analysis, which makes our results more credible. Future studies still need to supplement the assessment of patients' renal function and the endpoint of cardiovascular mortality to improve the credibility of the results.

\section{Conclusion}

Our conclusion proves that CA-AKI is an independent risk factor for the long-term death of diabetic patients, and the definition of $\mathrm{CA}-\mathrm{AKI}_{\mathrm{A}}$ is more suitable for diabetic patients. This is helpful for clinical patients to identify CA-AKI patients who are highly related to long-term death among diabetic patients, so as to give more kidney protection measures to improve their prognosis.

\section{Abbreviations}

CA-AKI: Contrast-associated acute kidney injury; CAG: Coronary angiography; PARs: Population attributable risks; HS-CRP: High-sensitivity C-reactive protein; AMI: Acute myocardial infarction; AKIN: Acute Kidney Injury Network; STEMI: ST-segment elevation myocardial infarction; IABP: Intra-aortic balloon pump; CHF: Congestive heart failure; NYHA: New York Heart Association; GFR: Glomerular filtration rate; ACEl: Angiotensin-converting enzymes inhibitor; ARB: Angiotensin receptor blocker; PCl: Percutaneous coronary intervention; SCr: Serum creatinine.

\section{Acknowledgements}

None.

\section{Authors' contributions}

$\mathrm{ZBL}, \mathrm{LL}, \mathrm{DHZ}, \mathrm{YL}$ and JFY contributed to the conception of the study; ZBL, LL, $\mathrm{DHZ}, \mathrm{MY}, \mathrm{LWL}, \mathrm{GZC}, \mathrm{ZDH}, \mathrm{YQY}$ and YBH contributed significantly to the data analysis and manuscript preparation; $Z B L, L L$, and $\mathrm{DHZ}$ performed the data analyses and wrote the manuscript; ZBL, $L L$ and $J L$ contributed to the design and statistical analysis of this study. All authors have read and approved the manuscript

\section{Funding}

The study is supported by the National Natural Science Foundation of China (Grant Nos. 81670339 and 81970311), the Beijing Lisheng Cardiovascular Pilot Foundation (Grant No. LHJJ201612127), and the Science and Technology Planning Project of Guangdong Province (Grant No. 2014B070706010). The funding bodies played no role in the design of the study and collection, analysis, and interpretation of data and in writing the manuscript.

\section{Availability of data and materials}

The datasets generated and/or analysed during the current study are not publicly available due data privacy regulation by Guangdong Provincial People's Hospital, but are available from the corresponding author on reasonable request.

\section{Ethics approval and consent to participate}

The research was approved by the ethics research Committee of Guangdong Provincial People's Hospital, and all participants signed the informed consent (Approval Number: GDREC2010112H). 


\section{Consent for publication}

Not applicable.

\section{Competing interests}

The authors declare that they have no competing interests.

\section{Author details}

${ }^{1}$ The First School of Clinical Medicine, Guangdong Medical University, Zhanjiang 523808, China. ${ }^{2}$ Department of Cardiology, Dongguan TCM Hospital, Dongguan 523000, China. ${ }^{3}$ Department of Cardiology, Guangdong Provincial Key Laboratory of Coronary Heart Disease Prevention, Guangdong Cardiovascular Institute, Guangdong Provincial People's Hospital, The Affiliated Guangdong Provincial People's Hospital of South China University of Technology, Guangdong Academy of Medical Sciences, Guangzhou 510080, China. ${ }^{4}$ The Second School of Clinical Medicine, Southern Medical University, Guangzhou 510515, China.

Received: 27 Auqust 2020 Accepted: 9 November 2020 Published online: 16 November 2020

\section{References}

1. Goldberg A, Hammerman H, Petcherski S, Zdorovyak A, Yalonetsky S, Kapeliovich M, et al. Inhospital and 1-year mortality of patients who develop worsening renal function following acute ST-elevation myocardial infarction. Am Heart J. 2005;150(2):330-7.

2. Mitchell AM, Kline JA, Jones AE, Tumlin JA. Major adverse events one year after acute kidney injury after contrast-enhanced computed tomography. Ann Emerg Med. 2015;66(3):267-74 e4.

3. Sato A, Aonuma K, Watanabe M, Hirayama A, Tamaki N, Tsutsui H, et al. Association of contrast-induced nephropathy with risk of adverse clinical outcomes in patients with cardiac catheterization: from the CINC-J study. Int J Cardiol. 2017;227:424-9.

4. Centola M, Lucreziotti S, Salerno-Uriarte D, Sponzilli C, Ferrante G, Acquaviva $\mathrm{R}$, et al. A comparison between two different definitions of contrast-induced acute kidney injury in patients with ST-segment elevation myocardial infarction undergoing primary percutaneous coronary intervention. Int J Cardiol. 2016;210:4-9.

5. Chen SQ, Liu Y, Smyth B, Li HL, Sun GL, Chen ZJ, et al. Clinical implications of contrast-induced nephropathy in patients without baseline renal dysfunction undergoing coronary angiography. Heart Lung Circ. 2019;28(6):866-73.

6. Lei L, Xue Y, Guo Z, Liu B, He Y, Song F, et al. A comparison between different definitions of contrast-induced acute kidney injury for long-term mortality in patients with acute myocardial infarction. Int J Cardiol Heart Vasc. 2020;28:100522

7. Guillon B, Ecarnot F, Marcucci C, Ducloux D, Chatot M, Badoz M, et al. Incidence, predictors, and impact on six-month mortality of three different definitions of contrast-induced acute kidney injury after coronary angiography. Am J Cardiol. 2018;121(7):818-24.

8. Akyuz S, Kemaloglu Oz T, Altay S, Karaca M, Yaylak B, Gungor B, et al. Association between glycosylated haemoglobin level and contrast-induced acute kidney injury in patients with type 2 diabetes mellitus. Cardiorenal Med. 2014;4(2):95-102.

9. Tsai TT, Patel UD, Chang TI, Kennedy KF, Masoudi FA, Matheny ME, et al. Validated contemporary risk model of acute kidney injury in patients undergoing percutaneous coronary interventions: insights from the National Cardiovascular Data Registry Cath-PCI Registry. J Am Heart Assoc. 2014;3(6):e001380

10. Chou RH, Huang PH, Hsu CY, Leu HB, Huang SS, Huang CC, et al. CHADS2 score predicts risk of contrast-induced nephropathy in stable coronary artery disease patients undergoing percutaneous coronary interventions. J Formos Med Assoc. 2016;115(7):501-9.

11. Mehran R, Aymong ED, Nikolsky E, Lasic Z, lakovou I, Fahy M, et al. A simple risk score for prediction of contrast-induced nephropathy after percutaneous coronary intervention: development and initial validation. J Am Coll Cardiol. 2004;44(7):1393-9.

12. Liu Y, Chen JY, Tan N, Zhou YL, Yu DO, Chen ZJ, et al. Safe limits of contrast vary with hydration volume for prevention of contrast-induced nephropathy after coronary angiography among patients with a relatively low risk of contrast-induced nephropathy. Circ Cardiovasc Interv. 2015;8(6):e001859.

13. Ad-hoc working group of E, Fliser D, Laville M, Covic A, Fouque D, Vanholder $R$, et al. A European Renal Best Practice (ERBP) position statement on the
Kidney Disease Improving Global Outcomes (KDIGO) clinical practice guidelines on acute kidney injury: part 1: definitions, conservative management and contrast-induced nephropathy. Nephrol Dial Transplant. 2012;27(12):4263-72.

14. Owen RJ, Hiremath S, Myers A, Fraser-Hill M, Barrett BJ. Canadian Association of Radiologists consensus guidelines for the prevention of contrast-induced nephropathy: update 2012. Can Assoc Radiol J. 2014;65(2):96-105.

15. Brar SS, Aharonian V, Mansukhani P, Moore N, Shen AY, Jorgensen M, et al. Haemodynamic-guided fluid administration for the prevention of contrastinduced acute kidney injury: the POSEIDON randomised controlled trial. Lancet. 2014;383(9931):1814-23.

16. Weisbord SD, Gallagher M, Jneid H, Garcia S, Cass A, Thwin SS, et al. Outcomes after angiography with sodium bicarbonate and acetylcysteine. $\mathrm{N}$ Engl J Med. 2018;378(7):603-14.

17. Nutritional anaemias. Report of a WHO scientific group. World Health Organ Tech Rep Ser. 1968:405:5-37.

18. Shuvy M, Beeri G, Klein E, Cohen T, Shlomo N, Minha S, et al. Accuracy of the Global Registry of Acute Coronary Events (GRACE) risk score in contemporary treatment of patients with acute coronary syndrome. Can J Cardiol. 2018:34(12):1613-7.

19. Roe MT, Chen AY, Thomas L, Wang TY, Alexander KP, Hammill BG, et al. Predicting long-term mortality in older patients after non-ST-segment elevation myocardial infarction: the CRUSADE long-term mortality model and risk score. Am Heart J. 2011;162(5):875-831.

20. Chalikias G, Drosos I, Tziakas DN. Contrast-induced acute kidney injury: an update. Cardiovasc Drugs Ther. 2016;30(2):215-28.

21. Mehran R, Dangas GD, Weisbord SD. Contrast-associated acute kidney injury. N Engl J Med. 2019;380(22):2146-55.

22. Lassnigg A, Schmidlin D, Mouhieddine M, Bachmann LM, Druml W, Bauer $P$, et al. Minimal changes of serum creatinine predict prognosis in patients after cardiothoracic surgery: a prospective cohort study. J Am Soc Nephrol. 2004;15(6):1597-605.

23. Pesarini G, Lunardi M, Ederle F, Zivelonghi C, Scarsini R, Gambaro A, et al. Long-term (3 years) prognosis of contrast-induced acute kidney injury after coronary angiography. Am J Cardiol. 2016;117(11):1741-6.

24. Budano C, Levis M, D'Amico M, Usmiani T, Fava A, Sbarra P, et al. Impact of contrast-induced acute kidney injury definition on clinical outcomes. Am Heart J. 2011;161(5):963-71.

25. Bachorzewska-Gajewska H, Malyszko J, Sitniewska E, Malyszko JS, Dobrzycki S. Neutrophil-gelatinase-associated lipocalin and renal function after percutaneous coronary interventions. Am J Nephrol. 2006;26(3):287-92.

26. Ni Z, Liang Y, Xie N, Liu J, Sun G, Chen S, et al. Simple pre-procedure risk stratification tool for contrast-induced nephropathy. J Thorac Dis. 2019;11(4):1597-610.

27. Zeng JF, Chen SQ, Ye JF, Chen Y, Lei L, Liu XQ, et al. A simple risk score model for predicting contrast-induced nephropathy after coronary angiography in patients with diabetes. Clin Exp Nephrol. 2019;23(7):969-81.

28. Zafrir B, Jaffe R, Rubinshtein R, Karkabi B, Flugelman MY, Halon DA. Impact of diabetes mellitus on long-term mortality in patients presenting for coronary angiography. Am J Cardiol. 2017;119(8):1141-5.

29. Chong E, Poh KK, Liang S, Tan HC. Risk factors and clinical outcomes for contrast-induced nephropathy after percutaneous coronary intervention in patients with normal serum creatinine. Ann Acad Med Singap. 2010;39(5):374-80.

30. Guo XS, Lin KY, Li HL, Chen JY, Zhou YL, Liu Y, et al. Preprocedural high-sensitivity C-reactive protein predicts contrast-induced nephropathy and longterm outcome after coronary angiography. Angiology. 2017;68(7):614-20.

31. Nemoto N, Iwasaki M, Nakanishi M, Araki T, Utsunomiya M, Hori M, et al. Impact of continuous deterioration of kidney function 6 to 8 months after percutaneous coronary intervention for acute coronary syndrome. Am J Cardiol. 2014;113(10):1647-51.

\section{Publisher's Note}

Springer Nature remains neutral with regard to jurisdictional claims in published maps and institutional affiliations. 